\title{
Circulating IGF1 and IGFBP3 in relation to the development of $\beta$-cell autoimmunity in young children
}

\author{
Aleksandr Peet ${ }^{1,2}$, Anu-Maaria Hämäläinen ${ }^{3}$, Pille Kool ${ }^{1}$, Jorma Ilonen ${ }^{4,5}$, \\ Mikael Knip ${ }^{3,6,7,8}$, Vallo Tillmann ${ }^{1,2}$ on behalf of the DIABIMMUNE Study Group* \\ ${ }^{1}$ Department of Pediatrics, University of Tartu, N. Lunini 651014 Tartu, Estonia, ${ }^{2}$ Children's Clinic of Tartu University \\ Hospital, N. Lunini 6, Tartu, Estonia, ${ }^{3}$ Children's Hospital and Jorvi Hospital, University of Helsinki and Helsinki \\ University Central Hospital, Helsinki, Finland, ${ }^{4}$ Immunogenetics Laboratory, University of Turku, Turku, Finland, \\ ${ }^{5}$ Department of Clinical Microbiology, University of Eastern Finland, Kuopio, Finland, ${ }^{6}$ Diabetes and Obesity \\ Research Program, University of Helsinki, Helsinki, Finland, ${ }^{7}$ Folkhälsan Research Center, Helsinki, Finland and \\ ${ }^{8}$ Department of Pediatrics, Tampere University Hospital, Tampere, Finland \\ *(Details of the DIABIMMUNE Study Group is listed in the Acknowledgements section)
}

\begin{abstract}
Objective: This study aimed at investigating the role of IGF1 and IGF binding protein 3 (IGFBP3) in the development of $\beta$-cell autoimmunity.

Methods: Five hundred and sixty-three subjects with HLA-conferred susceptibility to type 1 diabetes (T1D) were monitored for signs of seroconversion to positivity for insulin and/or GAD, IA2, and zinc transporter 8 autoantibodies by the age of 3 years. In 40 subjects who developed at least one autoantibody, IGF1 and IGFBP3 plasma concentrations were measured and compared with 80 control subjects who remained negative for autoantibodies, and were matched for age, sex, country of origin, and HLA genotype. The increments of IGF1, IGFBP3, and IGF1/IGFBP3 molar ratio before and after seroconverison were compared with corresponding time intervals in controls.

Results: The IGF1 concentrations at the age of 12 months and the IGF1/IGFBP3 ratio at the age of 24 months were lower in the autoantibody-positive children $(P<0.05)$. The increase in circulating IGFBP3 was significantly higher in the autoantibodypositive children before seroconversion than in the corresponding time intervals in controls $(0.43 \mathrm{mg} / \mathrm{l} ; 95 \% \mathrm{Cl} 0.29-0.56 \mathrm{vs}$ $0.22 \mathrm{mg} / \mathrm{l} ; 95 \% \mathrm{Cl} 0.10-0.34 \mathrm{mg} / \mathrm{l} ; P<0.01)$. Children carrying the high-risk HLA genotype had lower plasma IGF1 and IGFBP3 concentrations at the age of 24 months than those with low-risk genotypes $(P<0.05$ and $<0.01$ respectively).

Conclusions: Circulating IGF1 and IGFBP3 appear to have a role in early development of $\beta$-cell autoimmunity. The decreased IGF1 concentrations in children with the high-risk HLA genotype may contribute to the reduced growth previously described in such children.
\end{abstract}

\section{Introduction}

A growing body of evidence indicates an important role of insulin-like growth factor 1 (IGF1) in the regulation of islet $\beta$-cell growth, survival, and metabolism, with effects suggested to provide protection against type 1 diabetes (T1D) $(1,2,3,4,5)$. The ability of the pancreas to generate new $\beta$-cells in response to an increased metabolic demand
(C) 2015 European Society of Endocrinology Printed in Great Britain or after injury has been described in experimental diabetes models and, importantly, in infants with T1D (6). The possible role of IGF1 in the regeneration of $\beta$-cells is based on studies demonstrating an increased IGF1 expression in focal areas of regeneration in rats and dogs with partial pancreatectomy $(1,2)$. Further studies showed that IGF1 
increases the replication and proliferation of pre-existing $\beta$-cells after damage, (3) and protects $\beta$-cells from apoptosis (4). Moreover, several studies have demonstrated that IGF1 is also involved in the regulation of immune tolerance. For example, the expression of IGF1 in the pancreatic islets of transgenic mice protects islets from lymphocytic infiltration, counteracts cytotoxicity and insulitis induced by damage with multiple low doses of streptozotocin (5). In another mouse model, the IGF1 expression in the liver suppresses the progression of autoimmune diabetes and is associated with decreased islet inflammation (7).

The liver is the principal source of IGF1, producing up to $80 \%$ of circulating IGF1 (8), while the other $20-25 \%$ is synthesized locally by various tissues and acts mostly in an autocrine or paracrine manner (9). The role of circulating IGF1 in paracrine and autocrine regulation has not been fully understood. However, it has been shown that treatment with IGF1 protects islets against cytokinemediated inhibition of insulin secretion and cell death by apoptosis (10), implying an important role of circulating IGF1 in the survival of pancreatic islets. There have also been studies demonstrating that the administration of IGF1 into the systemic circulation reduces the severity of insulitis and delays the onset of diabetes in non-obese diabetic mice $(11,12)$.

The vast majority of IGF1 is bound to a family of six structurally and evolutionally related IGF-binding proteins (labelled as IGFBP 1-6), mostly to IGFBP3 $(13,14)$. The majority of IGF1 circulates in a large $(150 \mathrm{kDa})$ ternary complex with IGFBP3 and an acid-labile subunit (ALS) (14). The major role of IGFBP3 is the transport of IGF1, prolonging its half-life time, and controlling its access to the IGF1 receptor (15). However, IGF-binding proteins also have functions that are considered to be IGF1 independent $(15,16)$. The possible role of those IGF1 independent actions in the pathogenesis of diabetes is not clear, but some cross-sectional studies have observed that individuals with impaired glucose tolerance or T2D have lower IGFBP1 and higher IGFBP3 levels when compared to controls $(17,18)$. A large, prospective case-control study has demonstrated a strong positive association between circulating IGFBP3 and T2D (19).

As the growth hormone (GH)-IGF1 axis is the major determinant of childhood growth, the increased linear growth observed in children with T1D before the manifestation of the disease $(20,21)$ implies a possible role of IGF1 in the pathogenesis of T1D in humans. Some previous studies have reported that the childhood growth is related, at least partly, to different HLA genotypes conferring risk or protection against T1D $(22,23,34)$. In particular, our previous work has demonstrated that subjects with the high-risk HLA genotype had significantly slower linear growth and weight gain compared to those with low-risk HLA genotypes (22). To our knowledge, the possible interaction between the IGF1/IGFBP3 system and HLA genotypes has not been studied before. Moreover, despite a large body of evidence implicating a role for the IGF1/IGFBP3 system in the development of T1D $(1,2,3,4$, $5,7,11,12$ ), there is only one study on circulating IGF1 and IGFBP3 concentrations in prediabetic children with early signs of $\beta$-cell autoimmunity, i.e. positivity for diabetes-associated autoantibodies (24). That study did not find any difference between the level of IGF1 or IGFBP3 in subjects developing autoantibodies compared to those without autoantibodies (24). Therefore, because of the paucity of relevant studies, we set up a study to investigate the possible role of circulating IGF1 and IGFBP3 in the development of diabetes-associated autoantibodies in children with HLA-conferred susceptibility to T1D during the first 3 years of life.

\section{Subjects and methods}

\section{Study population}

The study subjects were derived from 258 Estonian and 305 Finnish children with HLA-conferred susceptibility to $\mathrm{T} 1 \mathrm{D}$, monitored for the development of diabetesassociated autoantibodies from birth up to the age of 36 months as a part of the DIABIMMUNE study. We included all 17 autoantibody-positive cases from Estonia (four with multiple autoantibodies, including one case that developed T1D by the age of 2.4 years) and all 23 autoantibody-positive cases from Finland (eight with multiple antibodies, including three cases that developed T1D by the age of 3.2, 3.7, and 2.6 years). In addition, for each case we selected two controls from the same DIABIMMUNE cohort with no diabetesassociated autoantibodies matched for sex, country of origin, and HLA-genotype and date of birth that were as close as possible. In this way 80 controls were selected for 40 autoantibody-positive subjects. All children were born between September 2008 and August 2010. The Estonian and Finnish study subjects were monitored according to the same protocol. The local Ethics Committees approved the study and the parents of all children gave written informed consent to participation in the study. 


\section{HLA genotyping}

HLA genotyping was performed with a PCR-based lanthanide-labeled hybridization method using time-resolved fluorometry for detection as previously described (25). Initially, the samples were analyzed for the presence of HLA $D Q B 1{ }^{*} 02, \quad D Q B 1{ }^{*} 03: 01, \quad D Q B 1{ }^{*} 03: 02$, and $D Q B 1{ }^{*} 06: 02 / 3$ alleles, as described by Kiviniemi et al. (26). Depending on the result of the initial analysis, the further analyses involved a low-resolution $D Q B 1$ fullhouse typing, DQA1 typing with three allele-specific probes, and subtyping of $D R 4$ (25). Samples positive for the $D Q A 1{ }^{*} 05-D Q B 1{ }^{*} 02$ combination (i.e. the DR3-DQ2 haplotype) and/or those with $D Q B 1{ }^{*} 0302 / 4$ without the presence of $D R B 1{ }^{*} 0403 / 6$ (DR4-DQ8) were included into the study if no protective haplotype (i.e. $D Q B 1{ }^{*} 06: 02 / 3$, $D Q B 1{ }^{*} 05: 03$, or the combinations of $D Q A 1 * 05$ $D Q B 1{ }^{*} 03: 01$ or $\left.D Q A 1{ }^{*} 02: 01-D Q B 1{ }^{*} 03: 03\right)$ was found.

According to Hekkala et al. (27), all subjects were divided into three groups, depending on their HLA alleles. The subjects with the combination of two susceptibilityassociated haplotypes, i.e. the DR3-DQ2/DR4-DQ8 genotype, were categorized as the high-risk group $(n=18)$, those carrying the DR4-DQ8/X genotype $(\mathrm{X}=\mathrm{a}$ nonprotective allele, but not DR3-DQ2) as a group with moderate risk $(n=57)$, and those with the DR3-DQ2/Y genotype ( $\mathrm{Y}=$ a non-protective allele, but not $\mathrm{DR} 4-\mathrm{DQ} 8)$ as a group with low, although increased, risk for T1D $(n=45)$.

\section{Diabetes-associated autoantibodies}

Insulin autoantibodies (IAAs), and antibodies to glutamic acid decarboxylase (GADA), insulinoma-associated 2 (IA2A), and zinc transporter 8 antibody (ZnT8A) were analyzed with specific radiobinding assays, as described by Knip et al. (28). The cut-off level was 2.80 relative units
(RU) for IAA, 5.36 RU for GADA, 0.78 RU for IA2A, and $0.61 \mathrm{RU}$ for ZnT8A. All samples obtained from cord blood (0 months) and at the follow-up visits at the ages of 3, 6, $12,18,24$, and 36 months were analyzed for those four biochemical autoantibodies. Islet cell antibodies were analyzed with indirect immunofluorescence on the human blood group 0 donor pancreas from all samples from any child testing positive for one or more of the biochemical autoantibodies. The detection limit was 2.5 Juvenile Diabetes Foundation units.

\section{IGF1 and IGFBP3 measurements}

Plasma concentrations of IGF1 and IGFBP3 were measured with a solid-phase, enzyme-labeled chemiluminescent immunometric assay with the IMMULITE 2000 analyzer (Diagnostic Products, Los Angeles, CA, USA), according to the manufacturer's protocols. The detection limit for IGF1 was $25 \mu \mathrm{g} / \mathrm{l}$. According to Elmlinger et al. (29), the intra-assay and inter-assay coefficients of variability for that method are $<4$ and $8 \%$, respectively, for IGF1 and $<4.5$ and $7 \%$ respectively for IGFBP3. In autoantibody-positive subjects, plasma IGF1 and IGFBP3 concentrations were measured from samples obtained at the age when seroconversion to positivity for at least one autoantibody was detected (T1) and at the closest time points before (T0) and after seroconversion (T2). For children with multiple autoantibodies, the IGF1 and IFGBP3 concentrations were measured from all available time points. In controls (autoantibody-negative children) IGF1 and IFGBP3 were analyzed from samples taken at the same time points as in the corresponding case children. The number of subjects studied at different time points is presented in Table 1.

Table 1 Numbers of IGF1 and IGFBP3 measurements at different ages in subjects with different HLA-related risk for T1D.

\begin{tabular}{|c|c|c|c|c|c|c|c|}
\hline \multirow[b]{3}{*}{ Age in months } & \multicolumn{6}{|c|}{ HLA risk-groups } & \multirow{3}{*}{$\begin{array}{l}\text { Number of subjects } \\
\text { with seroconversion }\end{array}$} \\
\hline & \multicolumn{2}{|c|}{ Low risk $(n=45)$} & \multicolumn{2}{|c|}{ Moderate risk $(n=57)$} & \multicolumn{2}{|c|}{ High risk $(n=18)$} & \\
\hline & $A a b+(n=15)$ & $A a b-(n=30)$ & $\mathrm{Aab}+(n=19)$ & $A a b-(n=38)$ & $A a b+(n=6)$ & $\mathrm{Aab}-(n=12)$ & \\
\hline $0(n=5)$ & 1 & 3 & 0 & 1 & 0 & 0 & 0 \\
\hline $3(n=19)$ & 3 & 7 & 2 & 6 & 1 & 0 & 1 \\
\hline $6(n=39)$ & 6 & 11 & 5 & 11 & 2 & 4 & 4 \\
\hline $12(n=67)$ & 9 & 16 & 12 & 21 & 3 & 6 & 8 \\
\hline $18(n=98)$ & 12 & 18 & 16 & 34 & 6 & 12 & 12 \\
\hline $24(n=79)$ & 9 & 15 & 15 & 28 & 4 & 8 & 3 \\
\hline $36(n=54)$ & 5 & 7 & 10 & 23 & 3 & 6 & 11 \\
\hline
\end{tabular}

$\mathrm{Aab}-, \mathrm{Aab}+-$ autoantibody negative and autoantibody positive respectively. 


\section{Statistical analysis}

The data were analyzed with the R-program (R 2.15.2, GraphPad, San Diego, CA, USA) and SAS (SAS 9.2, SAS Institute, Inc., Cary, NC, USA). The molar ratio of IGF1/IGFBP3, the possible marker of free bioactive IGF1 in plasma (30), was calculated on the basis of molecular weights of $7.6 \mathrm{kDa}$ for IGF1 (31) and $42 \mathrm{kDa}$ for IGFBP3 (32). The normality of data distribution was controlled using the Kolmogorov-Smirnov test. In cases when the concentration of IGF1 was below the detection limit, a level of $25 \mu \mathrm{g} / \mathrm{l}$ was used for the statistical analysis.

To compare the possible differences in plasma IGF1 and IGFBP3 concentrations and IGF1/IGFBP3 ratios between subjects with different HLA-risk groups for T1D, the ANOVA test with post-hoc Tukey HSD analysis was used. If the data were not normally distributed, the Kruskal-Wallis test with the post-hoc Bonferroni (Dunn) $t$-test was applied. For comparison of IGF1, IGFBP3, and IGFI/IGFBP3 molar ratio between autoantibody-positive and negative subjects, an unpaired two-tailed Student's $t$-test or, in the case of data with a skewed distribution, the Mann-Whitney's $U$ test were applied.

The changes in plasma IGF1 and IGFBP3 concentrations and in IGF1/IGFBP3 ratio were calculated between the time point of seroconverion (T1) and the closest time points before seroconversion (T0) to positivity for at least one autoantibody (T1-T0), as well as the closest time points after seroconversion (T2-T1). In matched control subjects, the changes in IGF1 and IGFBP3 concentrations as well as in the IGF1/IGFBP3 ratio were calculated between the same time points corresponding to those used in the cases. The paired $t$-test was applied to compare the changes in IGF1, IGFBP3, and IGF1/IGFBP3 ratio between cases and controls.

For the subgroup of autoantibody-positive children with multiple autoantibodies $(n=12)$, a paired $t$-test analysis of possible changes in IGF1, IGFBP3, and IFGI/IGFBP3 ratio between the time points before and at the time of seroconversion to positivity for multiple antibodies was performed as well. In addition, the four subjects who progressed to clinical T1D were compared to their controls applying the paired $t$-test. A $P$ value $<0.05$ was considered statistically significant.

\section{Results}

\section{IGF1 and IGFBP3 age-related changes in relation to HLA risk genotypes for T1D}

In general, there is a rapid decline in IGF1 concentrations after birth up to the age of 6 months, followed by a gradual recovery until the age of 18 months, when the levels are comparable with those at birth. After that, the IGF1 concentrations continue to increase slowly. Similar agerelated changes were also seen in the IGF1/IGBP3 ratio. The IGFBP3 concentrations are, in contrast, lowest in cord blood and increase continuously throughout the study period. At the age of 24 months, the mean IGF1 concentration was significantly lower in the children carrying the high-risk HLA genotype for T1D in comparison with the low-risk group $(57.1 \mu \mathrm{g} / \mathrm{l}, 95 \%$ CI $45.1-$ $69.1 \mu \mathrm{g} / \mathrm{l}$ vs $84.0 \mu \mathrm{g} / \mathrm{l}, 95 \%$ CI $68.1-99.8 \mu \mathrm{g} / \mathrm{l}, P=0.02$; Fig. 1). Simultaneously, the mean IGFBP3 concentration in the high-risk group $(2.3 \mathrm{mg} / \mathrm{l}, 95 \%$ CI $2.1-2.6 \mathrm{mg} / \mathrm{l}$; $P<0.01$ ) was also significantly lower when compared with both the moderate-risk $(2.5 \mathrm{mg} / \mathrm{l}, 95 \%$ CI $2.4-2.7 \mathrm{mg} / \mathrm{l}$; $P<0.01)$ and low-risk groups $(2.9 \mathrm{mg} / \mathrm{l}, 95 \%$ CI $2.7-$ $3.2 \mathrm{mg} / \mathrm{l}$ ) (Fig. 2). There were no differences in the IGF1/IGFBP3 ratio at any time between the three HLA risk groups (Fig. 3).

\section{Comparison between autoantibody-positive and negative subjects}

There were no significant differences in plasma concentrations of IGF1 and IGFBP3 concentrations or

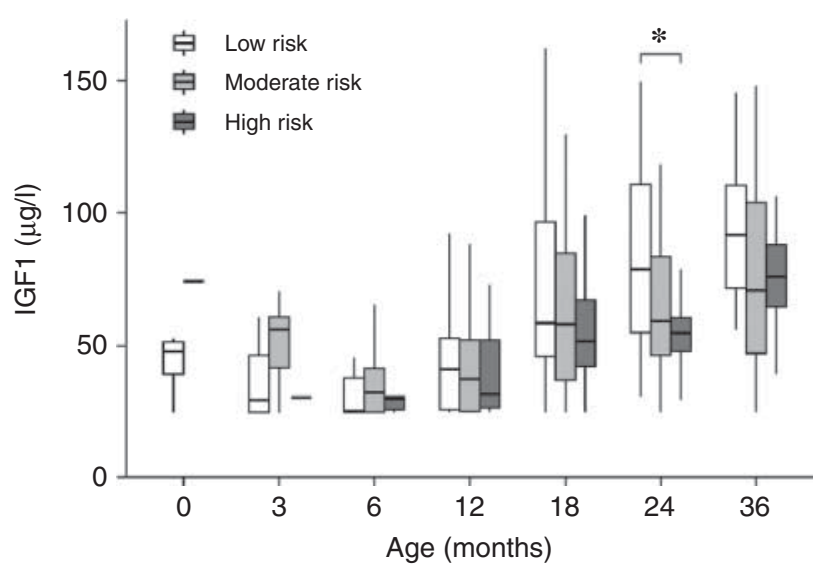

\section{Figure 1}

Box plot of plasma IGF1 concentrations over the first 3 years of life in the study participants in relation to their HLA risk genotype for type 1 diabetes. The ends of the whiskers show the lower and the upper quartile (Q1 and Q4 respectively). The horizontal bar at 0 months represents the value measured for a single subject from the moderate-risk group, and that at the age of 3 months is for a single subject from the high-risk group. The asterisk marks $P=0.02$ for the high risk vs the low-risk group. 


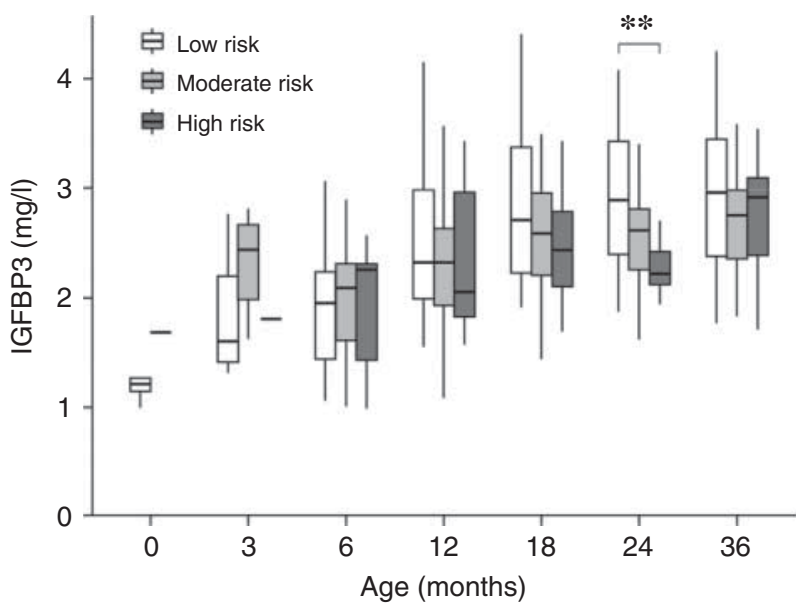

Figure 2

Box plot of plasma IGFBP3 concentrations over the first 3 years of life in the study participants in relation to their HLA risk genotype for type 1 diabetes. The ends of the whiskers show the lower and the upper quartile (Q1 and Q4 respectively).

The horizontal bar at 0 months represents the value measured for a single subject from the moderate-risk group, and that at the age of 3 months is for a single subject from the high-risk group. The two asterisks mark $P<0.01$ for the high risk vs both the moderate-risk and low risk groups.

IFG1/IGFBP3 ratio between the autoantibody-positive and negative children at any time point from birth up to the age of 36 months, except a slightly lower mean IGF1 concentration in autoantibody-positive subjects $(39 \mu \mathrm{g} / \mathrm{l}$, 95\% CI 30-48 $\mu \mathrm{g} / \mathrm{l})$ compared to the autoantibodynegative infants $(48 \mu \mathrm{g} / \mathrm{l}, 95 \% \mathrm{CI} 42-54 \mu \mathrm{g} / \mathrm{l})$ at the age of 12 months $(P<0.05)$, and a slightly lower IGF1/IGFBP3 ratio level in autoantibody-positive children at the age of 24 months $(0.136,95 \%$ CI $0.117-0.156$ vs $0.151,95 \%$ CI $0.140-0.161 ; P<0.05)$. In the four cases that progressed to clinical T1D, the concentrations of IGF1 and IGFBP3 and the IGF1/IGFBP3 ratio were not different from other cases or controls.

\section{Changes in IGF1, IGFBP3, and IFG1/IGFBP3 ratio before and after seroconversion}

When comparing the changes in IGF1 and IGFBP3 concentrations, as well as in the IFG1/IGFBP3 molar ratio between different time points, the mean increment in IGFBP3 concentration preceding the seroconversion (T1-T0) was significantly higher in autoantibody-positive children compared to the increase during the corresponding time interval in the autoantibody-negative subjects $(0.43 \mathrm{mg} / 1 \mathrm{95} \% \mathrm{CI} 0.29-0.56 \mathrm{mg} / \mathrm{l}$ vs $0.22 \mathrm{mg} / \mathrm{l}$, 95\% CI 0.1-0.34 mg/l; $P=0.005$; Fig. 4 ). In addition, there was a trend towards a decrease in mean IGF1 and IGFBP3 concentrations after seroconversion among the autoantibody-positive children (T2-T1, $P=0.06$ for both) compared to the autoantibody-negative subjects. A subcohort analysis of the autoantibody-positive children with multiple autoantibodies and their autoantibody-negative controls did not show any significant differences in the increase in mean IGF1 and IGFBP3 concentrations or in the IGF1/IGFBP3 molar ratio during the interval before and after seroconversion to multiple antibodies. The children who developed T1D showed similar trends to the other cases.

\section{Discussion}

In this study we observed several significant associations between the IGF1/IGFBP3 system on one hand and the development of diabetes-associated autoantibodies and HLA genotypes conferring risk for T1D on the other. First of all, we found that at the age of 24 months the mean IGF1 and IGFBP3 concentrations in subjects with the high-risk HLA genotype for T1D (DR3-DQ2/DR2-DQ8) were significantly lower compared to the subjects with

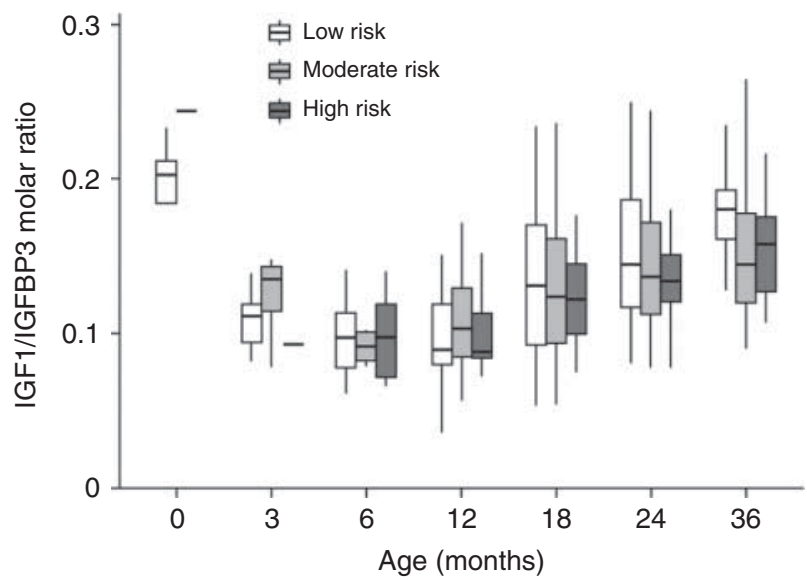

\section{Figure 3}

Box plot of plasma IGF1/IGFBP3 molar ratio over the first 3 years of life in the study participants in relation to their HLA risk genotype. The ends of the whiskers show the lower and the upper quartile (Q1 and Q4 respectively). The horizontal bar at 0 months represents the value measured for a single subject from the moderate-risk group, and that at the age of 3 months is for a single subject from the high-risk group. 


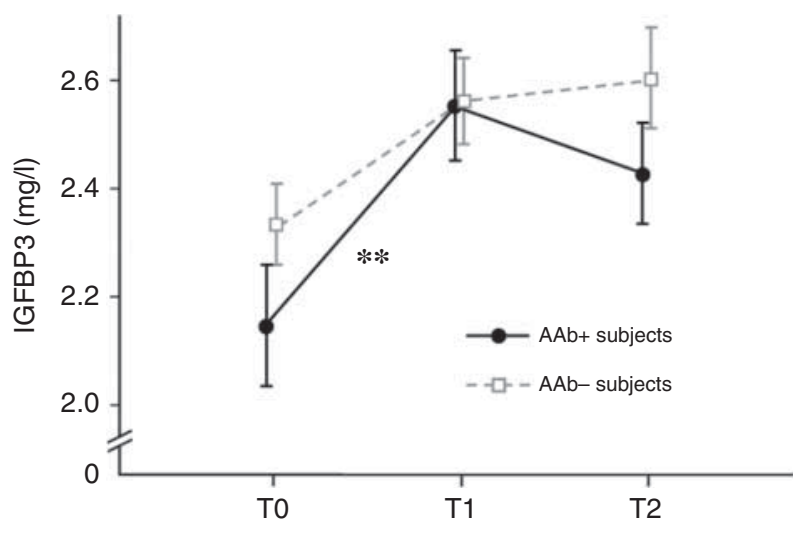

\section{Figure 4}

Mean plasma IGFBP3 concentrations in autoantibody-positive $(\mathrm{Aab}+)$ children compared to the controls (Aab-) before (T0), at (T1) and after (T2) seroconversion for at least one diabetesassociated autoantibody. The statistical standard error of the mean (S.E.M.) is shown by error bars. The increase preceding the seroconversion was significantly greater $(* * P=0.005)$ in the

$\mathrm{Aab}+$ children than during the corresponding time interval in the Aab - children.

low-risk HLA genotypes. The results are in line with our previous study in the entire DIABIMMUNE study cohort, where we found that by the age of 18-24 months the subjects with high HLA-risk genotypes for T1D demonstrated a pronounced slowdown in linear growth as well as in weight (22). The current results suggest that the decreased circulating IGF1 and IGFBP3 may be involved in the slower growth in children carrying the high-risk genotype. In the study by Beyerlein et al. (24), the association of IGF1 and IGFBP3 in relation to HLA status was not analysed.

The GH-IGF1 axis starts to play a major role in the regulation of human growth around the age of 2 years (33). This may explain why the difference in IGF1 and IGFBP3 concentrations between subjects with different HLA genotypes was seen only at the age of 24 months and not before. Accordingly, it would be interesting to follow these children to see whether a slower growth rate and lower IGF1 and IGFBP3 concentrations will continue to persist or whether this is just a temporary finding followed by some catch-up both in growth as well as in hormone concentrations. Studies in slightly older children $(23,34)$ and in adults (35), in whom increased HLA-conferred risk for T1D was observed to be associated with lower BMI, indicate that the former scenario is more likely to occur.
We suggest that the slower linear growth and weight gain in DIABIMMUNE subjects (22) and lower BMI in other children and adults with high HLA-conferred risk for T1D may be $(23,34,35)$ associated with lower circulating concentrations of IGF1 and IGFBP3. Since the mechanisms behind the HLA-conferred genetic susceptibility to T1D are poorly defined (36), we could speculate that the reduced IGF1 concentrations in subjects with the high-risk HLA genotype could explain, at least partially, the HLA-related risk for T1D, given that high IGF1 concentrations protect against the development of T1D $(4,5,7,10,11,12)$. However, Fourlanos et al. (35) recently proposed that an increased BMI simply promotes the development of T1D in subjects carrying lower-risk HLA risk genotypes by increasing the penetrance of lower-risk HLA genes, thus increasing the proportion of lower-risk HLA genes among subjects with higher BMI. The presence of HLA genotype-related differences in BMI in children without any signs of T1D, as was reported by Yang et al. (34), or as shown in the present study in children with early signs of $\beta$-cell autoimmunity, speaks against that suggestion.

The most important result of our study is probably the demonstration of a significantly higher increment in IGFBP3 before seroconversion to autoantibody positivity when compared to the corresponding time interval in autoantibody-negative subjects. In only one relevant study (24), the IGF1 and IGFBP3 concentrations were compared at certain time points irrespectively of the time of seroconversion, whereas our study looked at the rate of IGF1 and IGFBP3 increments before the time of seroconversion. This approach evaluates more directly the role of IGF1 and IGFBP3 in the process of autoimmunity development.

Our initial hypothesis was that there should be a significant difference in the increment of IGF1/IGFBP3 molar ratio as one of the proposed markers of bioavailable IGF1 (30). To a lesser degree, we expected to see differences in the changes in IGF1 or IGFBP3 concentrations. In our study, only the latter was observed. The interpretation of an isolated higher increment of IGFBP3 concentrations in autoantibody-positive subjects compared to autoantibody-negative ones represents a challenge, as the serum IGFBP3 concentration is predominantly regulated posttranslationally by stabilization through its GH-dependent binding partners IGF1 and ALS. Thus, at the serum level, IGFBP3 is GH-dependent (37), but at the transcriptional level is independent of GH (38). In some diseases, such as T1D and obesity, the serum IGF1 concentration is often within the normal range, whereas the GH level is high, 
reflecting some degree of disintegration of the GH/IGF1 axis (39). We suggest that this type of disintegration of the GH/IGF1 axis may exist to some extent also in subjects seroconverting to positivity for diabetes-associated autoantibodies. This suggestion is supported by the absence of any significant difference in the increment in the IGF1/IGFBP3 molar ratio when autoantibody-positive and negative children were compared in the period preceding the seroconversion (Fig. 4). Such a change in the IGF1/IGFBP3 molar ratio should be expected if the IGFBP3 increase in the two groups is not accompanied by a similar increase in the IGF1 concentration. As a matter of fact, a small difference in the mean IGF1/IGFBP3 molar ratio was actually seen between autoantibody-positive and autoantibody-negative subjects when the entire groups were compared at the age of 24 months. However, the observations regarding the IGF1/IGFBP3 molar ratio should be interpreted cautiously in terms of its biological role. In fact, it has recently been questioned whether the IGF1/IGFBP3 molar ratio is a reliable marker of free bioactive IGF1, as this has not been validated and proven experimentally (40). The molar ratio changes in the same direction as bioavailable IGF1 in some, but not all situations (39).

It is not clear whether IGFBP3 protects $\beta$-cells against autoimmune damage or accelerates the death of $\beta$-cells. Increasing IGFBP3 concentrations right before seroconversion to autoantibody positivity could be a compensatory reaction that increases the half-life of circulating IGF1, thus providing $\beta$-cell protection. An independent role of IGFBP3 in the development of autoimmune $\beta$-cell damage cannot be excluded. The IGF-independent apoptotic and growth-inhibitory effects of IGFBP3 have been seen in many different cell types (16); furthermore, in several large studies an association between IGFBP3 and the development of T2D has been demonstrated $(17,18,19)$. Accordingly, the role of the fast increase in plasma IGFBP3 concentration right before seroconversion will remain a subject for further studies.

In addition to the lower IGF1/IGFBP3 ratio at the age of 24 months in autoantibody-positive children compared to autoantibody-negative peers, we also found a similar difference in the IGF1 concentrations at the age of 12 months. Both findings are different from those reported by Beyerlein et al. (24), according to whom the IGF1 and IGFBP3 concentrations at 9 and 24 months of age did not differ between seropositive and seronegative subjects.

Our study has several limitations. First, the number of children who developed multiple autoantibodies or T1D was small. It is known that only a minority of subjects with one autoantibody will progress to clinical T1D (41). A second limitation is the modest sensitivity of the IGF1 assay with a lower detection limit of $25 \mu \mathrm{g} / \mathrm{l}$, as quite a large number of subjects (13 cases and 14 controls) had such results at the time point before seroconversion. The interpretation of the results provides also some challenges because of the relatively small number of IGF1 and IGBP3 samples in the particular subgroups based on HLA-risk genotypes and the autoantibody status. This drawback was due to the limited availability of plasma samples from the study participants. We should also take into consideration possible confounding factors, such as the duration of breastfeeding, which is known to influence the serum IGF1 concentrations (42). However, the differences in IGF1 and IGFPB-3 plasma concentrations were seen around 24 months of age, when the potential effect of breastfeeding should be marginal.

In conclusion, our study shows that circulating IGF1 and IGFBP3 may play a role in the development of $\beta$-cell autoimmunity in young children. The current results suggest a possible link between the previously reported association between HLA genotypes and linear growth rate, and weight gain in children with HLA-conferred susceptibility for T1D.

Declaration of interest

The authors declare that there is no conflict of interest that could be perceived as prejudicing the impartiality of the research reported.

\section{Funding}

The research received funding from the European Union Seventh Framework Programme FP7/2007-2013 under grant agreement number 202063 and was supported by grant number SF0180004s11 from the Estonian Ministry of Education and Science, as well as by the ETF9092 grant from the Estonian Science Foundation.

\section{Author contribution statement}

A Peet was responsible for the follow-up of the Estonian study cohort, and A-M Hämäläinen for the Finnish study cohort. A Peet was also responsible for the IGF1 and IFBP3 analyses, conceived the study along with V Tillmann and M Knip, participated in its design, and drafted the manuscript. P Kool designed and performed all statistical analyses. J llonen was responsible for HLA testing, defined the HLA subgroups and helped to draft the manuscript. M Knip was responsible for autoantibody assays. All co-authors read and approved the final manuscript.

\section{Acknowledgements}

We thank the DIABIMMUNE staff, all the local study nurses and participating families for their excellent collaboration. 
The DIABIMMUNE Study Group comprises the following investigators: Mikael Knip, PI (Children's Hospital, University of Helsinki), Katriina Koski, Coordinator (Institute of Clinical Medicine, University of Helsinki), Matti Koski (IT Manager, Institute of Clinical Medicine, University of Helsinki), Taina Härkönen (Children's Hospital, University of Helsinki), Samppa Ryhänen (Children's Hospital, University of Helsinki), Anu-Maaria Hämäläinen (Jorvi Hospital, Helsinki University Central Hospital), Anne Ormisson (Children's Clinic, Tartu University Hospital), Aleksandr Peet (Department of Pediatrics, Tartu University Hospital), Vallo Tillmann (Department of Pediatrics, Tartu University Hospital), Valentina Ulich (Ministry of Health and Social Development, Karelian Republic of the Russian Federation), Elena Kuzmicheva (Ministry of Health and Social Development, Karelian Republic of the Russian Federation), Sergei Mokurov (Ministry of Health and Social Development, Karelian Republic of the Russian Federation), Svetlana Markova (Children's Republic Hospital, Karelian Republic of the Russian Federation), Svetlana Pylova (Children's Republic Hospital, Karelian Republic of the Russian Federation), Marina Isakova (Perinatal Center, Karelian Republic of the Russian Federation), Elena Shakurova (Perinatal Center, Karelian Republic of the Russian Federation), Vladimir Petrov (Maternity Hospital $\mathrm{N}^{\circ} 1$, Petrozavodsk), Natalya V. Dorshakova (Petrozavodsk State University), Tatyana Karapetyan (Petrozavodsk State University), Tatyana Varlamova (Petrozavodsk State University), Jorma Ilonen (Immunogenetics Laboratory, University of Turku and Department of Clinical Microbiology, University of Eastern Finland, Kuopio), Minna Kiviniemi (Immunogenetics Laboratory, University of Turku), Kristi Alnek (Department of Immunology, University of Tartu), Helis Janson (Department of Immunology, University of Tartu) Raivo Uibo (Department of Immunology, University of Tartu), Tiit Salum (OÜ Immunotron, Tartu), Erika von Mutius (Children's Hospital, Ludwig Maximilians Universität, Munchen), Juliane Weber (Children's Hospital, Ludwig Maximilians Universität, Munchen), Helena Ahlfors (Turku Centre of Biotechnology, University of Turku and Åbo Akademi), Henna Kallionpää, (Turku Centre of Biotechnology, University of Turku and Åbo Akademi), Essi Laajala (Turku Centre of Biotechnology, University of Turku and Åbo Akademi), Riitta Lahesmaa (Turku Centre of Biotechnology, University of Turku and Åbo Akademi), Harri Lähdesmäki (Turku Centre of Biotechnology, University of Turku and Åbo Akademi), Robert Moulder (Turku Centre of Biotechnology, University of Turku and Åbo Akademi), Janne Nieminen (Department of Vaccination and Immune Protection, National Institute for Health and Welfare, Helsinki), Terhi Ruohtula (Department of Vaccination and Immune Protection, National Institute for Health and Welfare, Helsinki), Outi Vaarala (Department of Vaccination and Immune Protection, National Institute for Health and Welfare, Helsinki), Hanna Honkanen (Department of Virology, University of Tampere), Heikki Hyöty (Department of Virology, University of Tampere and Tampere University Hospital) , Anita Kondrashova (Department of Virology, University of Tampere), Sami Oikarinen (Department of Virology, University of Tampere), Hermie J.M. Harmsen (University Medical Center Groningen), Marcus C. De Goffau (University Medical Center Groningen), Gjal Welling (University Medical Center Groningen), Kirsi Alahuhta (Department for Welfare and Health Promotion, National Institute for Health and Welfare, Helsinki), and Suvi M. Virtanen, (Department for Welfare and Health Promotion, National Institute for Health and Welfare, Helsinki).

\section{References}

1 Smith FE, Rosen KM, Villa-Komaroff L, Weir GC \& Bonner-Weir S. Enhanced insulin-like growth factor I gene expression in regenerating rat pankreas. PNAS 199188 6152-6156. (doi:10.1073/pnas.88.14.6152)

2 Hayakawa H, Kawarada Y, Mizumoto R, Hibasami H, Tanaka M \& Nakashima K. Induction and involvement of endogenous IGF-I in pancreas regeneration after partial pancreatectomy in the dog. Journal of Endocrinology 1996149 259-267. (doi:10.1677/joe.0.1490259)
3 Agudo J, Ayuso E, Jimenez V, Salavert A, Casellas A, Tafuro S, Haurigot V, Ruberte J, Segovia JC, Bueren J et al. IGF-I mediates regeneration of endocrine pancreas by increasing $\beta$ cell replication through cell cycle protein modulation in mice. Diabetologia $2008 \mathbf{5 1}$ 1862-1872. (doi:10.1007/s00125-008-1087-8)

4 Castrillo A, Bodelón OG \& Boscá L. Inhibitory effect of IGF-I on type 2 nitric oxide synthase expression in Ins-1 cells and protection against activation-dependent apoptosis: involvement of phosphatidylinositol 3-kinase. Diabetes 200049 209-217. (doi:10.2337/ diabetes.49.2.209)

5 George M, Ayuso E, Casellas A, Costa C, Devedjian JC \& Bosch F. $\beta$ cell expression of IGF-I leads to recovery from type 1 diabetes. Journal of Clinical Investigation 2002109 1153-1163. (doi:10.1172/JCI0212969)

6 Meier JJ, Butler AE, Saisho Y, Monchamp T, Galasso R, Bhushan A, Rizza RA \& Butler PC. $\beta$-cell replication is the primary mechanism subserving the postnatal expansion of $\beta$-cell mass in humans. Diabetes 200857 1584-1594. (doi:10.2337/db07-1369)

7 Anguela XM, Tafuro S, Roca C, Callejas D, Agudo J, Obach M, Ribera A, Ruzo A, Mann CJ, Casellas A et al. Nonviral-mediated hepatic expression of IGF-I increases Treg levels and suppresses autoimmune diabetes in mice. Diabetes 201362 551-560. (doi:10.2337/db11-1776)

8 Sjögren K, Liu JL, Blad K, Skrtic S, Vidal O, Wallenius V, LeRoith D, Törnell J, Isaksson OG, Jansson JO et al. Liver-derived insulin-like growth factor I (IGF-I) is the principal source of IGF-I in blood but is not required for postnatal body growth in mice. PNAS 199996 7088-7092. (doi:10.1073/pnas.96.12.7088)

9 Ohlsson C, Sjögren K, Jansson JO \& Isaksson OG. The relative importance of endocrine versus autocrine/paracrine insulin-like growth factor-I in the regulation of body growth. Pediatric Nephrology 200014 541-543. (doi:10.1007/s004670000348)

10 Chen W, Salojin KV, Mi Q-S, Grattan M, Meagher TC, Zucker P \& Delovitch TL. Insulin-like growth factor (IGF)-I/IGF-binding protein-3 complex: therapeutic efficacy and mechanism of protection against type 1 diabetes. Endocrinology 2004145 627-638. (doi:10.1210/en. 2003-1274)

11 Mabley JG, Belin V, John N \& Green IC. Insulin-like growth factor I reverses interleukin-1 $\beta$ inhibition of insulin secretion, induction of nitric oxide synthase and cytokine-mediated apoptosis in rat islets of Langerhans. FEBS Letters 1997417 235-238. (doi:10.1016/S00145793(97)01291-X)

12 Bergerot I, Fabien N, Maguer V \& Thivolet C. Insulin-like growth factor-1 (IGF-1) protects NOD mice from insulitis and diabetes. Clinical and Experimental Immunology 1995102 335-340. (doi:10.1111/j.13652249.1995.tb03786.x)

13 Jones JI \& Clemmons DR. Insulin-like growth factors and their binding proteins: biological actions. Endocrine Reviews 199516 3-34. (doi:10.1210/edrv-16-1-3)

14 Butler AA, Gallaher BW, Ambler GR, Gluckman PD \& Breier BH. IGF-I and IGF-binding protein-3 in plasma of GH-deficient rats. Journal of Endocrinology 1996150 67-76. (doi:10.1677/joe.0.1500067)

15 Kim HS. Role of insulin-like growth factor binding protein-3 in glucose and lipid metabolism. Annals of Pediatric Endocrinology \& Metabolism 201318 9-12. (doi:10.6065/apem.2013.18.1.9)

16 Johnson MA \& Firth SM. IGFBP-3: a cell fate pivot in cancer and disease. Growth Hormone \& IGF Research 201424 164-173. (doi:10.1016/j.ghir. 2014.04.007)

17 Rajpathak SN, McGinn AP, Strickler HD, Rohan TE, Pollak M, Cappola AR, Kuller L, Xue X, Newman AB, Strotmeyer ES et al. Insulinlike growth factor-(IGF)-axis, inflammation, and glucose intolerance among older adults. Growth Hormone \& IGF Research 200818 166-173. (doi:10.1016/j.ghir.2007.08.004)

18 Frystyk J, Skjaerbaek C, Vestbo E, Fisker S \& Orskov H. Circulating levels of free insulin-like growth factors in obese subjects: the impact of type 2 diabetes. Diabetes/Metabolism Research and Reviews 199915 314-322. (doi:10.1002/(SICI)1520-7560(199909/10)15:5<314::AIDDMRR56 > 3.0.CO;2-E) 
19 Rajpathak SN, He M, Sun Q, Kaplan RC, Muzumdar R, Rohan TE, Gunter MJ, Pollak M, Kim M, Pessin JE et al. Insulin-like growth factor axis and risk of type 2 diabetes in women. Diabetes $2012 \mathbf{6 1} 2248-2254$. (doi:10.2337/db11-1488)

20 Bognetti E, Riva MC, Bonfanti R, Meschi F, Viscardi M \& Chiumello G. Growth changes in children and adolescents with short-term diabetes. Diabetes Care 199821 1226-1229. (doi:10.2337/diacare.21.8.1226)

21 Ljungkrantz M, Ludvigsson J \& Samuelsson U. Type 1 diabetes: increased height and weight gains in early childhood. Pediatric Diabetes 20089 50-56. (doi:10.1111/j.1399-5448.2007.00360.x)

22 Peet A, Hämäläinen AM, Kool P, Ilonen J, Knip M, Tillmann V \& DIABIMMUNE Study Group . Early postnatal growth in children with HLA-conferred susceptibility to type 1 diabetes. Diabetes/Metabolism Research and Reviews 201430 60-68. (doi:10.1002/dmrr.2449)

23 Yang J, Lernmark A, Uusitalo UM, Lynch KF, Veijola R, Winkler C, Larsson HE, Rewers M, She JX, Ziegler AG et al. Prevalence of obesity was related to HLA-DQ in 2-4-year-old children at genetic risk for type 1 diabetes. International Journal of Obesity 201438 1491-1496. (doi:10.1038/ijo.2014.55)

24 Carlsson A, Kockum I, Lindblad B, Engleson L, Nilsson A, Forsander G, Karlsson AK, Kernell A, Ludvigsson J, Marcus C et al. Low risk HLA-DQ and increased body mass index in newly diagnosed type 1 diabetes children in the Better Diabetes Diagnosis study in Sweden. International Journal of Obesity 201236 718-724. (doi:10.1038/ijo.2011.122)

25 Beyerlein A, Thiering E, Pflueger M, Bidlingmaier M, Stock J, Knopff A, Winkler C, Heinrich J \& Ziegler AG. Early infant growth is associated with the risk of islet autoimmunity in genetically susceptible children. Pediatric Diabetes 201415 534-542. (doi:10.1111/pedi.12118)

26 Mikk M-L, Kiviniemi M, Laine A-P, Härkönen T, Veijola R, Simell O, Knip M \& Ilonen J. The Finnish Paediatric Diabtes Register. The HLA$B \star 39$ allele increases type 1 diabetes risk conferred by HLA-DRB1*04:04DQB1*03:02 and HLA-DRB1*08-DQB1*04 class II haplotypes. Human Immunology 201475 65-70. (doi:10.1016/j.humimm.2013.09.008)

27 Kiviniemi M, Hermann R, Nurmi J, Ziegler AG, Knip M, Simell O, Veijola R, Lövgren T, Ilonen J \& TEDDY Study Group. A highthroughput population screening system for the estimation of genetic risk for type 1 diabetes. An application for the TEDDY (The Environmental Determinants of Diabetes in the Young) study. Diabetes Technology \& Therapeutics 20079 460-472. (doi:10.1089/dia. 2007.0229)

28 Hekkala A, Ilonen J, Knip M \& Veijola R. Family history of diabetes and distribution of class II HLA genotypes in children with newly diagnosed type 1 diabetes: effect on diabetic ketoacidosis. European Journal of Endocrinology 2011165 813-817. (doi:10.1530/EJE-11-0376)

29 Knip M, Virtanen SM, Seppa K, Ilonen J, Savilahti E, Vaarala O, Reunanen A, Teramo K, Hämäläinen AM, Paronen J et al. Dietary intervention in infancy and later signs of $\beta$-cell autoimmunity. New England Journal of Medicine 2010363 1900-1908. (doi:10.1056/ NEJMoa1004809)

30 Elmlinger MW, Kühnel W, Weber MM \& Ranke MB. Reference ranges for two automated chemiluminescent assays for serum insulin-like growth factor I (IGF-I) and IGF-binding protein 3 (IGFBP-3). Clinical
Chemistry and Laboratory Medicine 200442 654-664. (doi:10.1515/ CCLM.2004.112)

31 Juul A, Dalgaard P, Blum WF, Bang P, Hall K, Michaelsen KF, Müller J \& Skakkebaek NE. Serum levels of insulin-like growth factor (IGF)-binding protein-3 (IGFBP-3) in healthy infants, children, and adolescents: the relation to IGF1, IGF2, IGFBP-1, IGFBP-2, age, sex, body mass index, and pubertal maturation. Journal of Clinical Endocrinology and Metabolism 199580 2534-2542. (doi:10.1210/jcem.80.8.7543116)

32 Rinderknecht E \& Humbel RE. The amino acid sequence of human insulin-like growth factor I and its structural homology with proinsulin. Journal of Biological Chemistry 1978253 2769-2776.

33 Matsumoto T, Gargosky SE, Iwasaki K \& Rosenfeld RG. Identification and characterization of insulin-like growth factors (IGFs), IGF-binding proteins (IGFBPs), and IGFBP proteases in human synovial fluid. Journal of Clinical Endocrinology and Metabolism 199681 150-155. (doi:10.1210/jcem.81.1.8550744)

34 Karlberg J. On the construction of the infancy-childhood-puberty growth standard. Acta Paediatrica Scandinavica. Supplement 1989356 26-37. (doi:10.1111/j.1651-2227.1989.tb11237.x)

35 Fourolanos S, Elkassaby S, Varney MD, Colman PG \& Harrison LC. Higher body mass index in adults at diagnoosis of the slowly progressive form of type 1 diabetes mellitus is associated with lower risk HLA genes. Diabetes Research and Clinical Practice 2014104 e69-e71. (doi:10.1016/j.diabres.2014.03.009)

36 Xie Z, Chang C \& Zhou Z. Molecular mechanisms in autoimmune type 1 diabetes: a critical review. Clinical Reviews in Allergy \& Immunology 201447 174-192. (doi:10.1007/s12016014-8422-2)

37 Baxter RC \& Martin JL. Radioimmunoassay of growth hormonedependent insulinlike growth factor binding protein in human plasma. Journal of Clinical Investigation 198678 1504-1512. (doi:10.1172/ JCI112742)

38 Olivecrona H, Hilding A, Ekström C, Barle H, Nyberg B, Möller C, Delhanty PJ, Baxter RC, Angelin B, Ekström TJ et al. Acute and shortterm effects of growth hormone on insulin-like growth factors and their binding proteins: serum levels and hepatic messenger ribonucleic acid responses in humans. Journal of Clinical Endocrinology and Metabolism 199984 553-560.

39 Frystyk J. Free insulin-like growth factors - measurements and relationships to growth hormone secretion and glucose homeostasis. Growth Hormone \& IGF Research 200414 337-375. (doi:10.1016/j.ghir. 2004.06.001)

40 Baxter RC. GF binding proteins in cancer: mechanistic and clinical insights. Nature Reviews. Cancer 201414 329-341. (doi:10.1038/ $\operatorname{nrc} 3720)$

41 Knip M \& Siljander H. Autoimmune mechanisms in type 1 diabetes. Autoimmunity Reviews 20087 550-557. (doi:10.1016/j.autrev. 2008.04.008)

42 Grunewald M, Hellmuth C, Demmelmair H \& Koletzko B. Excessive weight gain during full breast-feeding. Annals of Nutrition \& Metabolism 201464 271-275. (doi:10.1159/000365033)
Received 7 December 2014

Revised 27 April 2015

Accepted 5 May 2015 